\title{
Filial obligations to elderly parents: a duty to care?
}

\author{
Maria C. Stuifbergen · Johannes J. M. Van Delden
}

Published online: 5 October 2010

(C) The Author(s) 2010. This article is published with open access at Springerlink.com

\begin{abstract}
A continuing need for care for elderly, combined with looser family structures prompt the question what filial obligations are. Do adult children of elderly have a duty to care? Several theories of filial obligation are reviewed. The reciprocity argument is not sensitive to the parent-child relationship after childhood. A theory of friendship does not offer a correct parallel for the relationship between adult child and elderly parent. Arguments based on need or vulnerability run the risk of being unjust to those on whom a needs-based claim is laid. To compare filial obligations with promises makes too much of parents' expectations, however reasonable they may be. The good of being in an unchosen relationship seems the best basis for filial obligations, with an according duty to maintain the relationship when possible. We suggest this relationship should be maintained even if one of the parties is no longer capable of consciously contributing to it. We argue that this entails a duty to care about one's parents, not for one's parents. This implies that care for the elderly is not in the first place a task for adult children.
\end{abstract}

Keywords Filial obligations - Care - Elderly parents · Adult children $\cdot$ Ethics $\cdot$ Health care policy

\section{Introduction}

In most cultures, some care for elderly parents by adult children is generally expected. These expectations may be found among elderly parents or adult children, in social

M. C. Stuifbergen $(\bowtie) \cdot$ J. J. M. Van Delden Julius Center for Health Sciences and Primary Care, University Medical Center Utrecht, Postbus 85500, 3508 GA Utrecht, The Netherlands

e-mail: m.stuifbergen@umcutrecht.nl norms and in the practice of allocation decisions for statefunded home help. Expectations of different parties often do not converge, which brings up the question what expectations are legitimate in the relationship between adult child and elderly parent.

A number of demographic trends increase the need for a clarification of filial expectations or obligations. In the future, there will be a larger percentage of elderly in our population (CBS 2009). Even if it is probable that they will be in better health than generations of elderly before them (Perenboom et al. 2004), it may be assumed that some forms of help will remain needed. At the same time, smaller nuclear families limit the availability of adult children for support giving. Furthermore, many nuclear families undergo changes in their composition over the course of their existence: divorces lead to the loss of a cohabiting parent, and new partnerships may introduce stepparents, stepsiblings and half siblings. An account of obligations of adult children towards elderly parents needs to allow for a variety of situations. In addition, western cultures nowadays are characterized by a high degree of individualization, in which being independent and developing one's own capacities is highly valued. The provision of support to family members, neighbors or friends is not self-evident under a doctrine of individualism, and the question what a correct interpretation of filial obligations ought to be becomes even more pressing.

We will present five theories of filial obligations, discussed in the literature over the past decades: filial obligations based on reciprocity, friendship, needs, an implicit promise and an argument based on the special goods that are derived from being in a parent-child relationship. We find the best arguments for filial obligations in the 'special goods argument', but these filial obligations are limited to maintaining the relationship. 


\section{Theories of filial obligations}

The argument of reciprocity

A popular idea of why we have obligations towards our elderly parents is that of reciprocity (Blieszner and Hamon 1992; Dykstra and Fokkema 2007): adult children owe something to their elderly parents because their parents have done much for them. Among these could be the fact that parents brought children into existence, nurtured them, educated them, and provided them with material things, among which the most basic ones of food, clothes and shelter: in short, they have created the conditions for children to exist and to use their capabilities. The idea that adult children owe their parents something in return can be viewed as a commonsense moral belief: it is a belief "that is entrenched in our moral framework and has been passed on through generations", it functions as a "basic premise in our moral practices", and it "expresses a legitimate expectation within a particular moral practice", i.e. it is a norm "that goes without saying" (Van den Hoven 2006, p.44).'

The idea that filial obligations are based on reciprocity may be widely shared in the public, but is strongly criticized by several scholars (e.g. (Collingridge and Miller 1997; English 1979)). These scholars bring forward that it is not at all clear what it is that children need to do 'in return' for their parents' upbringing. Keller (2006) distinguishes owing a "debt" from owing "gratitude", and finds both metaphors inadequate. 'Debt' refers to returning something on the basis of what is received, which at least two other authors find an inappropriate parallel for the exchange of favors between parents and children (English 1979; Wicclair 1990). English claims that a debt comes into existence in response to a favor ${ }^{1}$, and that the proper way to discharge a debt is to return the favor with a favor of equal magnitude. Wicclair (1990) adds that for debts, it should be clear when they can be considered to be 'discharged', which is not the case for filial obligations. English rejects the idea of the parent-child relationship as one in which favors are exchanged. She claims that past parental sacrifices are as good as irrelevant when the relationship between adult children and elderly parents is considered, and that the current relationship is what really matters (see below for a discussion of the friendship model of filial obligation). Wicclair instead asserts that not debt but gratitude is the appropriate basis of filial obligations. In contrast to debts which are determined by how much is received, gratitude is indeterminate and is responsive to the receiver's needs. In addition, gratitude is owed also for

\footnotetext{
1 With 'favor', English means 'requested favor', because 'unrequested sacrifices do not themselves create debts' (p. 354).
}

unrequested favors (Wicclair 1990, p. 175), thus taking the sting out of English' argument which states that it is not possible to owe parents a 'debt' on the basis of unrequested favors. Keller, however, in discussing the argument of gratitude, rejects it as the ground for filial obligations stating that "(duties of gratitude) are duties to show that you feel appropriately grateful (or perhaps to act as you would if you did feel appropriately grateful) for a given benefit" (2006, p. 257) whereas "filial duties are direct duties to help, respect, please or benefit parents" (Keller 2006, p. 259). In other words, showing gratitude is not enough-filial obligations require actions.

When we think about the argument of reciprocity as a commonsense moral belief, this belief does probably not involve keeping a checkbook of what is given and received, nor the notion that exactly that should be given which is received. It cannot be meant to imply the repayment of a debt in the literal sense, and to portray the argument thus makes it a caricature. The arguments against this norm are probably best understood in a context of duties and corresponding rights. The indeterminate nature of duties based on a broad interpretation of 'debt' or on gratitude makes it hard to define corresponding rights of parents to receiving a certain kind of support from their children. In the absence of such strict duties and rights, it would be hard to build policies based on such duties. But it would still be possible to defend the existence of an indeterminate, imperfect duty of gratitude at the individual level. However, although some form of reciprocity, indebtedness or gratitude may be part of someone's individual filial obligations, we claim that a theory of reciprocity has too narrow a scope if it portrays the parents as benefiting the child in childhood, and the adult child as the benefactor of elderly parents later in life. A quite different view on the parent-child relationship is offered by the friendship model of filial obligations.

\section{Duties emanating from friendship}

The friendship model of filial obligation focuses not on past favors or sacrifices by parents, but instead on the present relationship between an adult child and her parent. Adult children, it is argued, do not owe their parents anything in the sense of favors that need to be returned. What adult children owe their parents according to this argument is solely based on the present relationship between them, which ideally, is one of friendship. What parents have done for their children in the past is in this view considered as voluntarily distributed favors, of which it can only be hoped that they will lead to a form of friendship, in which support is exchanged out of a liking for each other (English 1979; Dixon 1995). English distinguishes two kinds of favors. In English' argumentation of the friendship model, 
favors that are asked for incur a debt on the beneficiary and need to be returned, for instance if I ask my neighbor to look after my house during my holiday. But if I do not ask anything and in my absence the neighbor is so kind as to mow my lawn twice weekly, this is not a favor that needs to be returned, but rather a kindness which may be responded to with a favor in return. In this last case, however, this would be done purely out of friendship, and not because I owe the neighbor anything. According to English, the favors of parents are more like mowing the lawn without being asked to. She concludes that adult children have no obligation towards their elderly parents, although they may consider doing them a favor in return, if they feel friendly towards them, and wish to cultivate their friendship. English acknowledges that previous sacrifices from the part of the parent may play a role in forming the friendship between parents and children, but emphasizes the importance of the current relationship. In addition, she stresses that the only appropriate motive for providing support, like the one in friendship, is love and concern about the other's welfare. Seen from this angle, if adult children unfortunately enough have no friendly feelings for their parents, they owe their parents nothing. As long as the friendship exists, friends are supposed to behave towards each other in a way that is appropriate in their friendship, which may include the exchange of favors in order to sustain the friendship. But when the friendship is over, the obligation to act as friends is over, and no favors are owed anymore, according to English. However, the experience of feelings of obligation for elderly parents is frequent, even if one does not feel friendly towards them, as Dixon (1995) acknowledges. To accommodate this feeling in the theory, Dixon extends the argument, such that for old times' sake we may feel obligated to those who are no longer our friends, although not so much as to our current friends ${ }^{2}$ (Dixon 1995).

In contrast to the reciprocity argument, the friendship argument of filial obligations focuses on the current relationship of adult children and elderly parents, and it accepts that adult children's support to their parents is contingent on these emotions. It makes a strong and attractive argument against a rigid rule of 'repayment' in favor of flexibility in support giving in connection with the type of relationship experienced. Why then would we object to such a model? We wish to mention two arguments. ${ }^{3}$ One of the reasons one could bring forward is that the continuous

\footnotetext{
${ }^{2}$ But note that this still excludes filial obligations if no friendly feelings were ever present.

3 An additional counterargument to English' position was pointed out to us by an anonymous reviewer, and is based on the observation that the parent-child relationship is one based on inequality, implying that even when parents become as vulnerable as children, they will never have that role, but remain parents.
}

stream of favors flowing from parents to children involves more than an unrequested favor like mowing the lawn while you are on holiday. ${ }^{4}$ And although lifelong gratitude may be asking too much in the case of a deteriorated parent-child relationship, one has to be very cynical if these past favors do not at least inspire some feeling of gratitude or indebtedness, regardless of them being performed by parents, neighbors or strangers. This rebuttal is a general one, applicable to any relationship in which one person is benefited very much by another person, but it is a feature which is present in many parent-child relationships. The other reason for not fully embracing the friendship model of filial obligation, and one which is cited by Dixon, is that the parent-child relationship simply is not a relationship between friends. One of the features of friendship is that the relationship is voluntarily engaged in by two separate people. This is clearly not the case in parent-child relationships. According to Dixon, the fact that the parentchild relationship does not conform to this model need not pose a problem. We could "recognise a multiplicity of types of friendship", and parent-child relationships, although different, may be "genuine friendships nonetheless" (Dixon 1995, p. 81-82). Our objection against this attempt to incorporate the parent-child relationship in the realm of friendships is that it passes over a distinguishing feature of the parent-child relationship almost as if it doesn't matter, whereas other scholars claim it to be the very basis of filial obligations: the involuntary nature of the relationship (Mills 2003; Keller 2006). Far from excluding friendship as a possible basis of filial actions, we are inclined to think that friendly feelings may be a motivator for support giving, but that it is not the only possible one. It seems rather that feelings of friendship may shape the amount and form of support giving of adult children to their parents, but that the basis for filial obligations lies elsewhere.

Parents' need as the basis for obligations

One could also say that adult children have an obligation towards their parents because they are in a unique position to provide the support needed. This line of thought is proposed by Goodin (1985), who presents a principle of protecting the vulnerable, and by Miller (2003), who sees filial obligations as a special case of beneficence, an imperfect Kantian duty.

Protecting the vulnerable according to Goodin means that "if one party is in a position of particular vulnerability to or dependency on another, the other has strong responsibilities

\footnotetext{
${ }^{4}$ In addition, one can question whether it is true that children do not ask for certain favors. In their behavior and needs, they can 'ask' without explicitly saying what they ask for.
} 
to protect the dependent party" (1985, p. 39). The reason why adult children have special responsibilities towards their parents is "precisely because their parents are most vulnerable to them; and the most important component of their vulnerability is emotional rather than material" (Goodin 1985, p. 88-89). Exactly how responsible someone is for someone else depends in this model on how strongly the other party is affected by the agent's actions and whether there are alternative sources to guarantee the other party's well being. It does not matter how the situation came into being, or whether other persons have a causal role in creating the situation. What matters is only whether the other party is vulnerable to the agent's actions at the time of acting.

According to Miller, the need of elderly parents obliges their adult children to act on the duty of beneficence, implying that "adult children must promote their aging parents' ends and happiness as those aging parents conceive of them" (Miller 2003, p. 193). But why should parents have any special status in Kant's principle of beneficence, when all persons are morally equal? Miller's answer is that the difference between promoting the ends of just anyone in need and those of one's own parents is that the parent's needs are more present. 'For in wishing I can be equally benevolent to everyone, whereas in acting I can, without violating the universality of the maxim, vary the degree greatly in accordance with the different object of my love.' (quote Kant by Miller 2003, p. 185).

Kittay (1999) criticizes the principle of vulnerability by saying that needs-based claims may not be legitimate, depending on the history of the situation. If a distant admirer claims that a certain person is the only one who can make him happy, that would make the distant admirer extremely vulnerable to this person's actions, yet no one will claim that she needs to fulfill his needs (Kittay's example).

Collingridge and Miller argue that from the existence of the need alone, we cannot deduce that adult children are the ones who are responsible for alleviating the need: "The existence of needs generates obligations on someone or other to satisfy those needs, but not adult children in particular" (Collingridge and Miller 1997, p. 124). In the same line, saliency of the need does not seem enough to explain why we should care for our parents, and not for instance for our elderly neighbor, whose needs may be at least as salient to us. We suspect that it is not saliency which is important, but something like emotional closeness, maybe shared history or in any case something that binds the adult child to the elderly parent in a morally relevant way.

It seems fair to say that the legitimacy of a needs-based claim depends on the type of claim and the relationship between claimant and potential benefactor. Some types of vulnerability do not produce legitimate claims, as in the example of the distant admirer. But if someone close to me, with whom I have a relational history, is vulnerable to my actions, his needs are meaningful to me. This does not mean that I should provide whatever the vulnerable party sees as their need. But because of our relationship I owe the other person a careful consideration of his needs.

A need alone cannot function as a moral guideline to decide who is responsible for satisfying the need, because the significance of the need and the obligation to fulfill it cannot be separated from the context in which the need arises. The relationship between an elderly parent and an adult child seems an appropriate context in which needs of one party are meaningful to the other party, but an argument based on needs alone cannot sufficiently explain why this is so. What is needed, is a clarification of the relationship between adult children and their elderly parents which shows why adult children would have a larger than average responsibility to satisfy needs of their elderly parents.

Filial obligations as an assumed promise

According to Hoff Sommers (1986), conventional expectations arise in certain social structures, such as friendship or nurturing relationships, and these expectations are comparable to making promises. In promising, the promisee can lay a claim on what the promiser has agreed to do. If parent-child relationships can be compared with relationships between promiser and promisee, and conventional expectations to promises, then the parent has a 'right' to what they expect from their children. In this view, the promise of the parent-child relationship is that adult children be "grateful, loyal, attentive, respectful and deferential to parents" (Hoff Sommers 1986, p. 447).

There are problems in the comparison of conventional expectations with a promise. It is true that promises oblige, but expectations simply do not have the same status, even if they arise in certain conventional relationship structures. To first equate conventional expectations with promises, and thus deduce obligations from conventions is at best an indirect way of describing obligations, as Smith points out: Why would we need to pretend that there is an unspoken promise when in fact there is not? At worst, the argument begs the question. Compare this view with the friendship view of filial obligations and the case (Smith 1993) of the neighbor spontaneously mowing my lawn in my absence. The neighbor might expect a favor in return, but I did not promise anything. To suggest that because of the neighbor's expectations I have a duty to provide the neighbor with a favor in return makes too much of expectations, however reasonable they may be. If I owe the neighbor a favor in return, it is not because of her expectations, but because of what she has done for me. Such an idea comes 
close to the argument of reciprocity. And what to think of parents who do not expect anything from their children, but rather hope for a pleasurable sustained relationship? Do high expectations oblige children more than low expectations? Finally, there is the impossibility of being "grateful, loyal, attentive, respectful and deferential" out of duty. Such feelings are hard to experience 'on demand'. It is also questionable whether an aging parent will be satisfied if a son grudgingly performs an obligation to do the grocery shopping. Hoff Sommers' answer to this observation is that duty and feelings are not mutually exclusive, but that duty comes first, if only to protect those whom no-one feels friendly to. But the question remains whether fulfilling these obligations and being a good carer is ever possible out of duty alone. According to Tronto (1993), good care is only possible with a sensitivity to the other person's need that is hard to imagine when provided without at least some empathy. It remains difficult to view filial obligations within a discourse on duties and rights. The variety of parent-child relationships and the fact that one has little choice in establishing this relationship with a particular person makes it difficult to define rigid duties as in the case of conscious choice, for which one is accountable.

Obligation stemming from the special good of a parentchild relationship

Although not many scholars have recently addressed the question of filial obligation, those who have defended some form of filial obligation have advocated a 'special goods theory' (Mills 2003; Keller 2006). Keller comments that "one of the reasons why the prevailing accounts of filial duty fail (...), is that they try to explain it by analogy, saying that being someone's grown child is just like being in someone's debt, or the recipient of someone's benevolence, or someone's friend. But being someone's child is not really like any of these things" (Keller 2006, p. 264). One of the special features of the parent-child relationship - as all family relationships - is that it is unchosen. Claudia Mills (2003) focuses on this feature in her account of filial obligations. We are simply stuck with the family we have and cannot decide to find new family, as we can in the case of friends. This is clear in the case of children. Children simply happen to be born to the parents they have. But Mills points out that the same could be said about parents. Although they-in this time, in our society, usually-decide to become parents, they do not choose the particular child they will be the parents of. They get a child, love it and care for it, whoever the child turns out to be. According to Mills that is exactly why the relationship is so valuable. In no other relationship do people take up such unconditional and far-reaching commitments as when they decide to care for a child, their child, no matter who this child turns out to be. The unconditional nature of most parents' love for their child is bound up with the unchosen character of it. If we could choose what kind of child we wanted to love, there would not be the same unconditional acceptance of whatever person this turns out to be. For children, it means that they are loved not because of who they are, but because of the relationship with the person who loves them. In practically no other human relationship is love so unconditionally given. The same is true for the child's love for the parent: it is given unconditionally, and without choice. According to Mills, "It is a great good to be in a relationship that is enduring and unconditional" (Mills 2003, p. 152). For Keller, “A healthy parent-child relationship adds value to the life of both parent and child for as long as it exists" (Keller 2006, p. 265).

Both Mills and Keller in similar ways distinguish two sorts of goods (Keller) or ends (Mills) in relation to the adult child-elderly parent relationship. Keller speaks of generic versus specific goods which are the product of the relationship between parents and children. Generic goods are those which can be obtained in a parent-child relationship, but "could just as well be provided by others" (Keller 2006, p. 266). Specific goods on the other hand are goods that can only be obtained in this particular relationship. A parent may for example value a child's keeping in contact, but not because she values someone-anyoneto call and talk to her. According to Keller, "the good in question is the good of having your child, the one you raised, love and care about, make an effort to keep in touch" (Keller 2006, p. 266). ${ }^{5}$ According to Mills, the good is being in the relationship itself. We can add that the relationship, besides being a good in its own right, is a portal to extended family relationships. The parent-child relationship is the node through which all other family relationships are connected, be they grandparents, siblings, uncles, aunts or nephews. Having family and being connected to others may add to one's sense of belonging in the world. This good, this having a family and being somehow connected to other people in this world, although a derivative from the parent-child relationship, must be considered a special good as well, because no other way exists to obtain the good. Because the parent-child relationship is a great good to both parties in the relationship, Mills says their duty is to continue the relationship. Mills argues that what the parties in the relationship owe to each other are those goods that can only be obtained in the relationship, and not goods than can be obtained elsewhere. ${ }^{6}$ This means

\footnotetext{
5 Mill's distinction between 'value-intrinsic' and 'value-extrinsic' ends of institutions is a similar distinction between generic and particular benefits of a relationship, and we will not discuss it here.

${ }^{6}$ Keller makes a similar argument, but does not follow it through as rigorously as Mills does. This is why we follow Mills determination of duties here.
} 
that material goods and money are not owed, but some contact and interest in each other's lives is.

\section{Obligations to care for or provide support to elderly parents}

We will now put some situations to the test and see where our point of view leads us in concrete cases.

Personal care and other services

An interesting case is how we should regard personal care and other services adult children often provide their parents. Are these special goods that cannot be obtained elsewhere, and is it therefore a duty to provide these goods to elderly parents? In many cases, we believe they are not special goods. As regards personal care, empirical research shows that most elderly parents in our society prefer formal care instead of informal care, and that the majority of adult children do not wish to provide hands-on care for their elderly parents either (Dykstra and Fokkema 2007; Stuifbergen et al. 2011). They would feel embarrassed by such an arrangement, judging personal care as inappropriate in the parent-child relationship. Thus, providing each other with the special goods of the relationship does not include a duty to provide personal care. However, things might be different if personal care from the child was a strong wish of the parent. In that case, the good of considerate, personal care might not be obtainable elsewhere. Then the question becomes relevant whether we ought to provide others with a good they cannot obtain from someone else. We have rejected such a duty above, with the criticism Kittay raised against the argument of vulnerability. Instead, we think the right focus here is on the relationship in which the request arises, what status the request has, and how much one feels it is appropriate in the relationship to provide what is asked for. As such, it is not different from any other request that turns up in the course of a relationship. If one feels inclined to agree to the request that is fine, and we can imagine there are many requests adult children wish to comply with wholeheartedly. But there is no duty to do so. Our position implies that elderly parents cannot claim services from their adult children. Not personal care, but not other services either. Surely many will object in a way that will go something like this: "Look, if my mum has a garden but can no longer mow the lawn, isn't it logical that I do it for her if I can? Wouldn't I be a bad daughter if I just let her sit with it?" Our answer would be that, if that is the way you feel about it, fine, and yes, please mow the lawn if you can. But if you hate mowing lawns, or live faraway, or simply consider yourself too busy to be bothered about mowing lawns, then the general answer would be: Your mother likes to have a garden. If she likes the garden, and likes to have a mown lawn but cannot mow it herself, she has to arrange for a gardener to mow her lawn. Or a friendly neighbor, for that matter. Maybe the objection would be that it would be too costly to hire all sorts of services that could easily be provided by the average healthy person. We suspect that many of the services rendered by adult children (and by family members and friends in general) are in fact a way of cost-containment. There is nothing wrong with that, as long as adult children feel happy to provide the services needed. But it is not a general duty.

Let us now take the argument to the extreme and picture an elderly father in an old, leaky house. The heater is broke, the sewer is clogged, the dishes are dirty, and dad is feeling depressed. Surely it would not be enough to come and visit once in a while, talk about the weather and say goodbye again? Wouldn't it be the child's duty to call a plumber, tidy up and invite father over to stay at her place for a while? At first glance, it seems harder to maintain that the adult child has no obligation to help father out. But at second thoughts we should be concerned with how the situation has come about. Father's problems should have been noted earlier in the sequence of events. And this is not solely the adult child's responsibility. The father's responsibility should not be overlooked, and this consists of first, taking care of himself and second, if he has trouble doing that, communicating this to others who can help him. If father takes the relationship with his child seriously, he has an obligation to communicate his problems at an earlier stage. If both parties wish to maintain a meaningful relationship, this is the father's obligation as much as the child's. Had the father communicated his problems earlier in time, it might not have been too difficult for the adult child to help father out, or help him sort himself out. We cannot say that the seriousness of the situation suddenly imposes extra duties on the adult child. Again, many adult children will wish to help their father in such circumstances. In a normal relationship, it would be unusual to completely leave the father to fend for himself. But the obligations of adult children do not include far-reaching caring tasks, if they are not inclined to do so.

\section{The case of dementia}

Do we have a duty to continue the relationship if the parent is not capable of participating in the relationship anymore? According to Mills not: "One implication of my view, which some will view as welcome, some as unwelcome, is that the obligation to participate in an ongoing relationship continues only when the relationship itself remains possible" (Mills 2003, p. 163). She considers care for a demented parent not as maintaining the relationship: "Heartless as it may seem to say this, I see little point in 
spending extensive time with someone who does not know me for who I am" (Mills 2003, p. 163).

We think Mills may be wrong here, and will argue that duties to aging parents do not end completely if the parent is demented and not capable of taking part in the relationship any longer. If we agree that continuing the relationship is an important obligation, and agree that it is not possible to have a one-sided relationship, then why should we doubt that the obligation ends when it is impossible to have a satisfactory mutual relationship? One reason is that it is hard to point out when exactly a relationship is over. It is often documented that patients with dementia react well to the presence of a well-known person, however estranged from the world around them they may be. It would be wrong to think that the relationship is valuable only in the case of equal or similar contributions to it. Even in the friendship model-with friendship as a blueprint for balanced relationships-there is room for a continued relationship even if the balance of favors has tipped to one side. "For old times' sake", we may continue to feel obligated when a friendship is over, out of respect for the former friendship (Dixon 1995). If a relationship has been mutually satisfying, we suggest that it is still our duty not to deny the other party the good of continuing the relationship, especially when this can be done with little cost to ourselves. In the situation described the parent is vulnerable to the adult child's actions. We do not have a moral duty to respond to every claim made on the basis of vulnerability-see our discussion of the vulnerability argument above. But in this case the need of the parent is legitimate because of the shared history. It does not seem right to end contact completely because one of the parties in the relationship is against their will excluded from consciously participating in it. The content of the relationship will certainly change, but that is no reason to end the relationship completely.

But there are more reasons not to end the relationship, reasons tied to the relationship itself, which we feel flow naturally from the original argument. One of them is the value of knowing that the relationship continues even when one is not consciously aware of it, and no longer has control over the relationship. The prospect of having someone you know and trust at your side when you are no longer consciously aware of what is going on around you will color the relationship at the time you are aware of it. To know that someone cares for you even when there seems no reason to do so anymore may strengthen the relationship at the time when there is no need for such care. To continue the relationship also when the parent is demented, is in fact the mirror image of the unconditional love the parent feels for a child. No-one would choose to build up a relationship with a demented person because of the person's characteristics, but if this demented person is your mother, you continue the relationship because it is there and you are an important part of it.

At the same level of argument, we wish to argue that one should continue the relationship because the way one experiences a relationship now colors the perception of the relationship in past times. To abandon one's demented parent may lead to a devaluation of the moments once shared together, whereas to continue contact may enrich the moments lived before ${ }^{7}$.

These arguments to continue the relationship with a demented parent have nothing to do with gratitude or vulnerability. They are concerned with preserving the relationship because it continues to provide benefits to both parties, albeit of a different kind.

What if someone does not care?

According to Mills, we have an obligation to continue the relationship because of the great good it is and the special goods it provides. Although this seems a credible conclusion, it might be that this step is taken a bit too quickly. What if someone just does not care, and is not interested in the good of the kind between parents and children? Why would that person still be obliged to maintain the relationship? If we only have a duty to maintain the relationship when it provides us with the special goods it is intended to, then there would not be a reason to continue the relationship when it does not. Mills leaves room for the discontinuation of the relationship if this is more harmful than beneficial, but points out that as long as the relationship has the potential of offering the special goods it could provide, we have a duty to continue it. But what if someone does not see the point of continuing the relationship, not because the relationship is harmful, but because it does not bring her anything she considers valuable? It is hard to see how a continuation of the relationship would be obliged in that case, without either paternalistically imposing our family values on others, or referring to something as reciprocity, gratitude or vulnerability. But even though we cannot point out an obligation to do so, it is probably with some idea of reciprocity, or some respect for the history of the relationship that adult children find it difficult to deny their parents their keeping in touch completely, even if sometimes they have to go to great lengths to do so. Most of us have some idea that the relationship is a special one and for that reason try harder to maintain it. But if, as in the example above, someone genuinely does not see the point of being in a relationship with one's parent, it would be very paternalistic to maintain that it is still an obligation

\footnotetext{
$\overline{7}$ One may also benefit from continuing the relationship because taking care of others may make one a better person, as suggested to us by an anonymous reviewer.
} 
because the relationship is a potential source of a special good.

\section{Conclusion}

One of the welcome aspects of an account of filial obligation based on special goods is that it arrives at a plausible and well-defined description of adult children's duties ${ }^{8}$ - at least clearer than any of the other accounts. Maintaining the relationship does not exclude providing other goods, but this is supererogatory. The obligation to maintain the relationship is not dependent on the actual benefits the child received. It thus circumvents problems observed with the argument of reciprocity. It is also based on a more credible account of the relationship than the friendship argument offers. Although friendly feelings may be present, most of us experience that family bonds are unlike friendships and carry some obligation with them. Doing one's best to maintain the relationship seems the minimum required. We have argued that maintaining the relationship is a duty also when one of the parties is no longer capable of being an equal partner in the relationship because of dementia. How much more parents and adult children wish to do for each other on top of their maintaining the relationship is up to their own discretion, and will depend on the content of their relationship. Because both parties are in a meaningful relationship, the needs of an elderly parent have a moral force, and adult children will often want to comply with them, in the light of the relationship they value. But it is not the duty of an adult child to provide for their parent financially, or by taking up demanding care tasks. It is up to the actors in the relationship to decide the exact content of the relationship, as long as they are maintaining it.

This is then what we claim our filial obligation regarding care for elderly parents is: to maintain the relationship, and by maintaining contact, trying to be sensitive to one's elderly parents' needs. If there is at least a minimal relationship with the parent possible, our duty is a duty to care about our parents, in the way that Tronto (1993) describes as the first phase of caring: "noting the existence of a need and making an assessment that this need should be met" ( $p$. 106). What should be done when a need is perceived depends on the context of the relationship. Caring about an elderly parent does not necessarily entail care-giving. In most instances it will probably mean taking care of aspects of the situation, for instance supervising the care provided by others.

\footnotetext{
${ }^{8}$ Mills is most explicit in this respect.
}

\section{Policy implications}

If filial obligations are no more than a personal duty to try and maintain the relationship with one's elderly parents, then certainly all policy attempts that try and force members of a family to provide more informal care must be rejected. Our position implies that care for elderly is not a duty of adult children, nor the payment of such care. This means that either private or public services should be the main providers of care for the elderly. It is this last option which is suggested by Daniels (1988) en by Jecker (2002), arguing from a framework of justice. It would be unjust for some to have to take up large care tasks, depriving them of many other opportunities in life. It would also be unjust that only those with adult children willing and able to take care of them should receive the care they need. This task should therefore not be assigned to adult children, but instead to public services, leaving open possibilities for support to parents and children who wish to provide care within the family circle.

Acknowledgments We would like to thank anonymous reviewers for insightful comments on earlier versions of this paper, and Rieke van der Graaf for constructive suggestions.

Open Access This article is distributed under the terms of the Creative Commons Attribution Noncommercial License which permits any noncommercial use, distribution, and reproduction in any medium, provided the original author(s) and source are credited.

\section{References}

Blieszner, R., and R.R. Hamon. 1992. Filial responsibility: attitudes, motivators, and behaviors. In Gender, families, and elder care. Sage focus editions, vol. 138, ed. J.W. Dwyer, and R.T. Coward, 105-119. Thousand Oaks, CA, US: Sage Publications Inc.

CBS. 2009. Statline. Electronic database of Statistics Netherlands. http://statline.cbs.nl/StatWeb/publication/?DM=SLNL\&PA=71867 ned $\& D 1=a \& D 2=a \& D 3=1,1 \& H D R=T \& S T B=G 2, G 1 \& V W=T$. Accessed June 2010.

Collingridge, M., and S. Miller. 1997. Filial responsibility and the care of the aged. Journal of Applied Philosophy 14: 119-128.

Daniels, N. 1988. Am I my parents' keeper? An essay on justice between the young and the old. New York: Oxford University Press.

Dixon, N. 1995. The friendship model of filial obligations. Journal of Applied Philosophy 12: 77-87.

Dykstra, P.A., and T. Fokkema. 2007. Persoonlijke zorgnormen: bereidheid te geven én te ontvangen. (Personal norms of care: willingness to give and willingness to receive). In Blijvend in balans. Een toekomstverkenning van informele zorg, ed. De Boer A. and Timmermans J. M. Den Haag: Sociaal en Cultureel Planbureau.

English, J. 1979. What do grown children owe their parents? In Having children. Philosophical and legal reflections on parenthood, ed. O. O'Neill, and W. Ruddick. Oxford: Oxford University Press.

Goodin, R.E. 1985. Protecting the vulnerable. A reanalysis of our social responsibilities. Chicago: The University of Chicago Press. 
Hoff Sommers, C. 1986. Filial morality. The Journal of Philosophy 83: 439-456.

Jecker, N.S. 2002. Taking care of one's own: justice and family caregiving. Theoretical Medicine 23: 117-133.

Keller, S. 2006. Four theories of filial obligation. The Philosophical Quarterly 56: 254-274.

Kittay, E.F. 1999. Love's labor. New York: Routledge.

Miller, S.C. 2003. Filial obligation, Kant's duty of beneficence, and need. In Care of the aged, ed. James M. Humber, and Robert F. Almeder, 169-198. Totowa: Humana-Pr. Biomedical Ethics Reviews.

Mills, C. 2003. Duties to aging parents. In Care of the aged, ed. J.M. Humber, and R.F. Almeder, 147-166. Totowa: Humana Press.

Perenboom, R., L. van Herten, G. van den Bos, and H. Boshuizen. 2004. Trends in disability-free life expectancy. Disability and Rehabilitation 26: 377-386.
Smith, P. 1993. Family responsibility and the nature of obligation. In Kindred matters, ed. D. Tietjens Meyers, K. Kipnis, and C.F. Murphy Jr, 41-58. Ithaca: Cornell Univrsity Press.

Stuifbergen, M.C. 2011. Filial obligations today. Moral practice, perception and ethical theory [thesis]. Utrecht University, Utrecht.

Tronto, J. 1993. Moral boundaries. A political argument for an ethic of care. New York: Routledge.

Van den Hoven, M. 2006. A claim for reasonable morality. Commonsense morality in the debate on the limits of morality [dissertation]. Utrecht University, Utrecht (NL).

Wicclair, M.R. 1990. Caring for frail elderly parents: past parental sacrifices and the obligations of adult children. Social Theory and Practice 16: 163-189. 